\title{
A intervenção de intelectuais na reforma educacional do governo militar: discursos e práticas nas escolas municipais de Curitiba
}

\author{
The intervention of intellectuals in educational reform of the \\ military government: \\ discourses and practices in public schools in Curitiba
}

Iêda Viana*

RESUMO

O artigo trata da intervenção de intelectuais da Universidade Federal do Paraná, no processo da reforma escolar proveniente da Lei 5692/71 e das implicações dessa lei, especialmente com relação à disciplina escolar de História, que passa a ser integrada a uma área de ensino, junto com a Geografia, conforme o Parecer no 853/71 do CFE, com a institucionalização dos Estudos Sociais no currículo do ensino de primeiro grau, nas escolas municipais de Curitiba, através de um projeto específico: "Estudos Sociais a partir da longa duração", com a consultoria dos intelectuais. O objetivo geral foi investigar como se deu essa intervenção no processo reformador e seus resultados, ou seja, como o projeto foi difundido em seu discurso curricular e praticado na sala de aula, destacando permanências e transformações nesse campo de conhecimento escolar. A história oral e documentos escritos serviram de aporte metodológico para a pesquisa, cujos resultados revelam que nem sempre as estratégias políticas do governo militar (19641985) tiveram o êxito almejado e que a intervenção de intelectuais nesse processo pode ter servido para reforçar a manutenção de propostas conservadoras por tempo mais prolongado, embora introduzindo algumas mudanças.

Palavras-chave: História da Educação. Reforma. Intelectuais. Estudos sociais. Práticas escolares.

\footnotetext{
* Doutora. Professora e Pesquisadora do Programa de Mestrado e Doutorado em Educação da Universidade Tuiuti do Paraná e do curso de graduação em História; Coordenadora do Curso de Especialização Patrimônio, Memória e Gestão Documental, com foco de interesse na área de História da Educação e Ensino de História e História das Instituições Escolares.
} 


\section{ABSTRACT}

The article analyses the intervention of intellectuals of the Federal University of Paraná, in the process of school reform from the Law 5692/71 and the implications of the law, especially with regard to school discipline of History, which is integrated into a teaching area, along with Geography, as Opinion No. $853 / 71$ of the CFE, with the institutionalization of Social Studies at the primary school education curriculum in public schools in Curitiba, through a specific project: "Social Studies from the long term" with the consulting intellectuals. The overall objective was to investigate how did this intervention in the reform process and its results, that is, as the project was widespread in their curricular speech and practiced in the classroom, highlighting continuities and transformations that school knowledge field. Oral history and written sources served as a methodological contribution to the research, the results show that not all the political strategies of the military government (1964-1985) had the desired success and that the intervention of intellectuals in this process may have served to reinforce maintaining conservative proposals for a longer time, while introducing some changes.

Keywords: History of Education. Reform. Intellectuals. Social studies. School practices.

\section{Introdução}

As importantes batalhas históricas dos intelectuais têm ocorrido nos elementos produtivos do poder - o controle do símbolo ou seja, as distinções, as categorias e as regras nas construções das relações sociais e da identidade (POPKEWITZ, 1997, p. 256).

No dia 31 de março de 2014, o golpe político que conduziu o país a uma ditadura completou 50 anos, o que contribui para reavivar o debate e novas leituras sobre objetos de estudos diversos que envolvem este episódio da história brasileira. Este artigo aborda a questão da reforma curricular no ensino das humanidades decorrente da Lei 5692/71, no contexto daquele regime de exceção (1964-1985) e suas implicações no ensino de primeiro grau, especialmente com relação à disciplina escolar de História, que passou a se integrar a uma área de ensino - os Estudos Sociais -, junto com a Geografia em conformidade com aquela Lei e o Parecer $n^{\circ}$ 853/71.

A Lei 5692/71 foi criada em um contexto paradoxal, alvo de contestações e resistências, mas também de euforia e acordos tácitos por várias razões, especialmente em função do crescimento econômico e seus reflexos nos campos do emprego, da urbanização e da cultura do país, que contribuíram significativamente para a omissão e o apoio de boa parte da população às diretrizes desenvolvimentistas do governo. 
Em relação à educação e ao ensino de História, ainda são poucas as pesquisas que permitem entender como os diferentes agentes se inseriram nesse processo de mudanças políticas e culturais.

Assim, o objetivo geral foi investigar como se deu a intervenção intelectual naquele processo reformador, através da estruturação e implantação do projeto curricular "Estudos Sociais a partir da longa duração", nas escolas municipais de Curitiba, além de destacar como o mesmo foi apropriado e praticado na sala de aula, com a implantação daquela área de estudos.

Como objetivos específicos pretendeu-se identificar os agentes envolvidos, analisar o lugar social de suas falas e esquadrinhar os discursos e práticas dos Estudos Sociais, com o intuito de dar inteligibilidade ao que ocorreu no interior das escolas municipais de Curitiba.

A intervenção dos intelectuais sinalizou para a hipótese geral de que o aproveitamento de uma brecha no poder por parte desses agentes permitiu-lhes - através da perspectiva de mudança educacional (POPKEWITZ, 1997) -, embora ocupando um espaço estratégico, operar naquele momento num quadro de movimentos táticos (CERTEAU, 1994) à política educacional do município, encontrando as condições para estabelecer ao lado do projeto educativo oficial uma experiência alternativa.

Segundo Certeau (1994), as estratégias são comuns nos processos de regulação social e elaboradas num lugar próprio, demarcado por uma visão macro, por quem detém o poder. Em contrapartida, as táticas, são elaboradas por quem exerce um papel secundário, aproveitando-se das oportunidades e, no caso investigado, podem ter sido usadas tanto pelos professores universitários, na estruturação e implantação do projeto alternativo, como pelos professores municipais frente às “inovações” curriculares daquela reforma.

Pensar as políticas educacionais é refletir não apenas em sua natureza de controle e de regulação social (POPKEWITZ, 1997), mas também sobre como se realiza o processo de apropriação ${ }^{1}$ das ordenações superiores, colocando em jogo atitudes de adesão, instaurando negociações, constituindo espaços, enquanto lugares praticados pelos usuários numa rede de lugares e relações que produzem poder e saber (CERTEAU, 1994).

O caráter alternativo do Projeto deveu-se à compreensão dos intelectuais de que seus fundamentos apresentavam condições de superar tanto as propostas tradicionais de ensino de História como a proposta oficial de institucionalização dos Estudos Sociais que vinha sendo implantada. Seu aporte teórico-metodológico foi buscado em obras do historiador

\footnotetext{
${ }^{1}$ A noção de apropriação para Chartier visa realizar "uma história social dos usos e das interpretações, referidos as suas determinações fundamentais e inscritas nas práticas específicas que a produzem" (1991: 180). Seu significado indica as duas dimensões: a ênfase nas interpretações, remetendo ao conceito de representações sociais; e o realce aos usos, orientando a investigação para as práticas sociais. É através da apropriação que se dá a operação de sentido por parte dos usuários.
} 
Fernand Braudel, um dos representantes do movimento historiográfico encaminhado pela revista Annales, que justamente se propunha a revolucionar a história, superando os paradigmas até então predominantes: o positivismo e o marxismo.

A reconstituição das práticas escolares, através da memória dos agentes escolares e do exame de documentos proporcionou visibilidade à invenção do cotidiano (CERTEAU, 1994). As fontes orais tiveram um papel importante na busca de inteligibilidade histórica, envolvendo a noção de memória enquanto representação. Para Certeau, a memória é a chave para compreensão dos movimentos táticos de reação dos sujeitos a imposições superiores e uma presença à pluralidade de tempos, a qual, graças à capacidade de acumular experiências, permanece oculta - como "escrituras invisíveis" - até o instante em que se revela no "momento oportuno" como lembrança. Ela é representação, mas também é prática, pois a construção de sentido se dá na relação com o outro (CERTEAU, 1996 p. 63).

A historiografia sobre o ensino de História tem contribuído para a construção de duas representações ${ }^{2}$ mais importantes sobre esse ensino com a institucionalização dos Estudos Sociais: a primeira é a do esvaziamento de conteúdos oriundos da ciência de referência - a História, na qual a transposição didática nos currículos de Estudos Sociais teria promovido o distanciamento que passou a existir entre os saberes escolares e os saberes acadêmicos; ${ }^{3}$ a segunda versão é a da manutenção dos referenciais teórico-metodológicos da História tradicional, permanecendo a primazia dos aspectos políticos, datas, personagens heroicos, batalhas, portanto, a perspectiva da História linear, evolucionista, factual (NADAI, 1985/1986, p.110). ${ }^{4}$

Daí o interesse em analisar aquele contexto cultural e político, muito mais complexo do que se tem pensado, mobilizando a reflexão sobre o significado histórico da implantação do projeto "Estudos Sociais a partir da longa duração". Principalmente por nele se identificar a preocupação de realizar a aproximação do saber escolar ao saber científico, pela mediação dos intelectuais.

$\mathrm{O}$ artigo discutirá inicialmente algumas questões que podem contribuir para identificar o lugar social da fala dos intelectuais. Num segundo momento serão feitas reflexões acerca da implantação dos Estudos Sociais nas escolas municipais, com destaque para o discurso curricular e suas práticas.

\footnotetext{
${ }^{2}$ Roger Chartier compreende representações sociais como esquemas ou conteúdos de pensamentos que, embora enunciados de modo individual, são de fato os condicionamentos não conscientes e interiorizados que fazem com que um grupo ou uma sociedade partilhe um sistema de representações e um sistema de valores comuns. (CHARTIER, 1986)

${ }^{3}$ O ensino tradicional de História, segundo Nadai (1992/1993), apesar das críticas realizadas articulava-se coerentemente com um determinado referencial teórico-metodológico da ciência de referência em sua vertente positivista.

${ }^{4}$ Além de Nadai (1985/1986), ver Schmidt; Cainelli (2004).
} 


\title{
1 O lugar social do intelectual
}

O Departamento de História da Universidade Federal do Paraná, em 1973, foi convidado pelo Ministério da Educação, para oferecer contribuições ao processo de institucionalização dos Estudos Sociais, em decorrência da Lei 5692/71, cuja concretização se deu inicialmente com palestra proferida pela historiadora Cecília Westphalen sobre o referencial teóricometodológico dos Annales, que admitia a aproximação das Ciências Sociais (WESTPHALEN, 2006), propiciando o embasamento aos Estudos Sociais, como determinava a legislação; e, num segundo momento, estruturando com outros intelectuais daquela universidade o projeto "Estudos Sociais a partir da longa duração", implantado em 1975 na rede escolar local, pelas condições que esta apresentava - anuência de sua administração, necessidade de adaptar-se à nova legislação e facilidade de acesso às escolas e professores.

\begin{abstract}
O Projeto [...] está [...] relacionado com o Seminário de Estudos Sociais para o Ensino de Primeiro Grau, promovido [...] em 1973, em Brasília, pelo MEC/DEF/CODEAT. Ali a professora Cecília Maria Westphalen apresentou a comunicação - a historiografia brasileira e as posições metodológicas da historiografia atual -, analisando a situação dos estudos e da pesquisa histórica no País, a renovação metodológica da História a partir, sobretudo, da "Escola de Annales", enfatizando [...] sua aproximação com as demais Ciências do Homem [grifo nosso] (UFPR. Relatório $\mathbf{n}^{0} 1$, 1976, p.35-36).
\end{abstract}

Segundo Germano (2000), as atitudes de adesão e imobilismo em favor da reforma constituiu uma tônica naquela conjuntura nacional. Muitos intelectuais apoiaram o regime militar e alguns ajudaram a implantar a reforma.

A intervenção intelectual em Curitiba pode ser compreendida como uma estratégia política governamental, mas também se reveste de um caráter tático, por sua intencionalidade acadêmica: levar à superação epistemológica da tradição escolar. ${ }^{5}$

Assim, torna-se fundamental proporcionar as condições históricas que possam trazer dúvidas à posição de vontade geral da qual pode estar falando o intelectual. Logo, pensar nas políticas educacionais, transformadas em currículos prescritivos, significa refletir sobre o lugar social que determinou seus discursos, com quais finalidades, estratégias ou táticas foram desenvolvidas tais práticas sociais.

Para compreender melhor o papel social dos intelectuais, naquele momento, cabe discutir determinadas características do movimento intelectual dos Annales e analisar a

\footnotetext{
${ }^{5}$ Certeau não compreendia essas categorias como estanques e polarizadas, ao contrário, indicava uma relação tensional entre ambas.
} 
influência desse campo historiográfico no Curso de História da universidade e no projeto "Estudos Sociais a partir da longa duração".

\subsection{Os Annales na historiografia}

A História contemporânea vem realizando uma rica discussão no campo da historiografia, incluindo no debate: o questionamento sobre o entrelaçamento entre o social, o político e o econômico, o particular e o geral, o individual e o coletivo; a tensão entre a liberdade individual e o determinismo das estruturas; a busca por uma história global que explicite as vinculações básicas entre os diferentes aspectos de uma realidade sociocultural. A difusão dessa ótica deve-se em grande parte à escola dos Annales.

As grandes tendências historiográficas que predominaram na segunda metade do século XX - a marxista, os Annales e o quantitativismo - surgiram e se articularam em torno de centros de interesse diversos. O paradigma dominante no século XIX, influenciado pelo historicismo e positivismo, foi sucedido no século XX. A inovação não está apenas na diversidade teórico-metodológica dessas tendências, mas na forma como operaram simultaneamente, sem que ocorressem substituições de uma pela outra.

Há, porém, uma diferença entre essas tendências: o marxismo e o quantitativismo tiveram projeção nas ciências sociais, de onde evoluíram até alcançar a historiografia, enquanto o movimento dos Annales se originou no próprio campo da investigação histórica, segundo Burke (1997), como reação à "escola metódica" - representativa da velha História. Esta exalta a erudição, a política e o acontecimento. Os adeptos dos Annales desprezam o acontecimento, insistem na longa duração, na atividade econômica, na organização social e na psicologia coletiva. Fazem críticas à velha História, prisioneira do factual, do acontecimento, da política e diplomacia, das biografias; privilegiando as elites, os Estados, as instituições, os momentos-chave (guerras, revoluções, pestes) e não considerando os processos que antecedem e envolvem esses fenômenos, nem a participação do povo.

A nova História renuncia à ênfase os poderosos, detém-se na história do povo: a história imóvel. A tendência da longa duração busca a sobrevivência e as transformações relativas aos grandes grupos, seja através da explicação dos fenômenos, que se prolongam no tempo, seja na história das colheitas, nos aumentos dos preços, nas taxas de natalidade e mortalidade, nos costumes e crenças.

Sob a influência das ciências sociais, a nova História realizou uma revolução epistemológica quanto ao conceito de tempo histórico (BURKE, 1997). A investigação no tempo longo reside em um esforço de superação do evento e seus corolários - história contínua, progressiva e irreversível, defende a existência de um tempo pluridirecionado, múltiplo, 
propondo para o seu controle a ênfase aos aspectos repetitivo, cíclico, constante, da vida dos homens. Sofreu também uma mudança com relação aos seus objetos, técnicas e métodos, transformando a própria noção de documento. Se antes os documentos eram relativos ao evento e ao sujeito, agora se relacionam ao campo econômico-social: "[...] à vida cotidiana das massas anônimas, a sua vida produtiva, a sua vida comercial, ao seu consumo, as suas crenças, as suas diversas formas de vida social" (REIS, 2000a, p.126). Ela assimila também novas abordagens das outras Ciências Sociais, como revelar as tramas do poder em diferentes dimensões da esfera humana, através do simbólico e do imaginário. Supera a narrativa descritiva, para incorporar uma narrativa explicativa e compreensiva.

Suas inovações podem ser assim sumariadas: substituição da tradicional narrativa de acontecimentos por uma história-problema; história de todas as atividades humanas; colaboração de outras ciências; proposição de uma teoria da multiplicidade do tempo social.

\subsection{A universidade e os Annales}

A Universidade Federal do Paraná, nos anos de 1960 e 1970, destacava-se como uma das instituições universitárias com forte influência dos Annales. Muitos de seus professores realizaram estudos em universidades francesas. Essa tendência encontra destaque nos trabalhos de Cecília Westphalen, além de Altiva Balhana e Brasil Pinheiro Machado e outros historiadores como Sérgio Nadalin, Carlos Antunes dos Santos, Rui Wachowicz, Oksana Boruszenko.

\footnotetext{
O curso de História passou a dar sua contribuição para os estudos acerca do homem em sociedade, a partir do final dos anos 50 , quando a professora Cecília Westphalen, de volta da Europa, trouxe para seus quadros uma concepção mais dinâmica de ensino e pesquisa.

Em 1959 foi aprovado o regulamento do Seminário de História, um centro de estudos e pesquisas destinado a dinamizar e organizar os trabalhos docentes e discentes do curso, com vistas às pesquisas [...]. (SIQUEIRA; TRINDADE, 1998, p.64).
Nomes como Louis Herry e Frédéric Mauro estiveram presentes, no decorrer da década de setenta, ministrando cursos na Universidade Federal do Paraná e sua influência, somada a de Fernand Braudel, é perceptível na produção científica de vários professores. (MARCHI et al.1992/1993, p. 135-136).

Tal efeito aparece ainda em dissertações de mestrado do curso de pós-graduação de História daquela universidade, a partir de sua instalação em 1972, "produzidas dentro desse mesmo quadro teórico-metodológico, com pequenas variações no recorte geográfico" (MARCHI, 1992/1993, p.136). 
No contexto do regime militar poucos se aventuravam a investigar numa perspectiva diferente, especialmente na esteira do marxismo.

Na década de 1980, a produção científica de História traz à tona novas orientações. Além da influência do movimento intelectual dos Annales, há as propostas teórico-metodológicas do marxismo e o impacto de obras como as de Foucault, Thompson, Hobsbawm, entre outros, que redesenham os quadros conceituais, de acordo com Marchi (1992/1993).

\title{
1.3 Os Annales no projeto "Estudos Sociais a partir da longa duração"
}

No contexto de efervescência cultural orientada pela historiografia francesa, houve interesse por parte dos intelectuais em expandir o debate acadêmico para as escolas de primeiro grau. Com a institucionalização dos Estudos Sociais, fundamentada na ideia de integração das áreas de conhecimento das humanidades, foi identificada uma oportunidade para realizar a superação do projeto educativo tradicional de História. O discurso do Projeto defendia a existência de um fosso entre:

\begin{abstract}
[a] prática cotidiana das escolas e o progresso das Ciências Sociais. Haja vista a História [...] continua tradicional, descritiva, narrativa, episódica, ou seja, na escola se pratica uma história fática, individualista, afasta-se das novas posições conceituais e metodológicas que há quarenta anos tomam de assalto à historiografia contemporânea. E porque o ensino está ligado ainda a concepções superadas das Ciências Sociais, é que não tem sido possível realizar a filosofia abrangente dos Estudos Sociais. $O$ ensino [...] não se renovará enquanto não se renovar[em] [...] [as] posições conceituais e metodológicas, abertas [...] às conquistas científicas e tecnológicas do mundo contemporâneo. (UFPR, Relatório $\left.\mathrm{n}^{\circ} .1,1976, \mathrm{p} .13-14\right)$.
\end{abstract}

Os intelectuais defendiam a reestruturação do ensino das humanidades através do embate com a produção científica contemporânea, ou seja, com a renovação da História representada pelos Annales, que propunha a aproximação entre as Ciências Sociais.

Nas memórias sobre o Projeto está evidente essa preocupação. $O$ princípio da interdisciplinaridade, que fundamentava a proposta oficial dos Estudos Sociais, na prática escolar brasileira enfrentava problemas na sua implantação. A área de Estudos Sociais permanecia reduzida a simples rubrica no currículo escolar, no qual se aglutinavam os conteúdos isolados da História e da Geografia. Mantinha-se a concepção tradicional de ensino de História na prática escolar. Era "como se tivessem mudado o rótulo da garrafa e o conteúdo permanecesse o mesmo... Por isso veio a proposta [...], para atender essa 
necessidade e integrar as áreas". (ALMEIDA, 2006). Era fundamental recorrer a um referencial que viesse a dar conta de mudanças.

Ao propor a implantação dos Estudos Sociais, a reforma municipal abre perspectivas para duas frentes de debate no campo acadêmico: a (re) discussão da noção de interdisciplinaridade 6 , posta inicialmente pelo discurso renovador da educação, nos anos de 1930, e alimentada por diferentes tendências nos anos de 1960-1970; e a incorporação de tendências teóricas e metodológicas de uma das ciências de referência, sob os princípios dos Annales, a quem os conhecimentos históricos e geográficos eram tão significativos e que, naquele Projeto, acabam afinal sofrendo certo esvaziamento, principalmente no caso da Geografia.

A recusa à História tradicional perpassa todo o discurso curricular, sugerindo o rompimento com o tempo histórico linear e com a abordagem que proporcionava exclusividade a determinados agentes históricos.

Existe é certo um tempo breve para todas as formas de vida. Mas ele não é tudo. A história tradicional trabalhou nele e sobre ele, atenta aos grandes fatos. A ruptura com a história tradicional é, sobretudo, uma alteração do tempo histórico tradicional. Não basta um dia, é preciso ver o recitativo da conjuntura, não só econômica, social, institucional. E, para além dos ciclos, é preciso ver as tendências seculares. [...]. Não pensar apenas no tempo curto, não pensar que os atores que fazem ruído sejam os mais autênticos, também os há silenciosos. (UFPR, Relatório $\mathrm{n}^{\circ} .1,1976$, p. 63-64).

Ao estruturar o Projeto, os intelectuais falam de um lugar social bem específico - a academia - e, nesta, de uma comunidade de leitores - influencida pelos Annales -, que detém um saber e um poder. Desse modo, justificam-se, colocando duas "razões fundamentais" para a sua contribuição: a responsabilidade social da universidade na produção de um saber escolarizável coerente com a produção da ciência de referência; e o interesse científico de que aqueles princípios teórico-metodológicos fossem "testados" na prática escolar.

$1^{\text {a }}$ A presença necessária da Universidade no processo global da Educação, contribuindo principalmente para superar o profundo fosso que existe entre o ensino na prática cotidiana das escolas e o progresso

\footnotetext{
${ }^{6}$ Embora seja necessário refletir historicamente sobre este conceito de interdisciplinaridade, que não tem o mesmo significado posto nos debates atuais. Naquele contexto a noção era compreendida pelos educadores mais com uma conotação de justaposição ou área globalizadora. A própria noção de articulação teórica e metodológica entre as ciências sociais que o movimento intelectual dos Annales defendia era de difícil apropriação pelos educadores.
} 
da ciência, cuja maior e melhor informação é ela detentora. Deste modo, sua contribuição deve ser, sobretudo, no que respeita aos conteúdos.

$2^{\mathrm{a}} \mathrm{O}$ interesse científico do Departamento de História em testar no ensino de $1^{\circ}$ grau, as proposições braudelianas da História, sobretudo os conceitos da multiplicidade do tempo social, tirando partido da longa duração, e a maior aproximação, sem fronteiras, das Ciências do Homem (UFPR. Relatório n ${ }^{\circ}$. 3,1977, p.9).

Beneficiando-se da conjuntura reformadora na área de humanidades, os intelectuais aproveitavam uma oportunidade histórica para realizar a transposição didática do saber acadêmico para o saber escolar e assim tentar a superação do "fosso" existente entre a universidade e a escola, entre a prática escolar cotidiana e a prática acadêmica: entre as "escolas e o progresso da ciência", o que revela a representação progressista dos intelectuais sobre seu próprio papel e o da ciência naquela reforma, conforme acepção de Popkewitz (1997).

Não obstante, ao optar pelo referencial teórico-metodológico que norteia a estruturação da nova área de estudos, os intelectuais não seguem simplesmente as orientações didáticopsicológicas, inspiradoras das experiências iniciais dos Estudos Sociais. Ao contrário, priorizam o conteúdo do ensino articulado ao método histórico, embora sem descuidar daquelas orientações.

A conciliação entre os interesses governamentais - pela necessidade de controle social no contexto de desenvolvimento urbano e de legitimação de suas políticas por parte da sociedade civil - e os objetivos dos intelectuais em difundir seus projetos científicos teria propiciado uma brecha na história, para que outro projeto educativo caracterizado como uma experiência alternativa a oficial pudesse se instalar em algumas escolas municipais, naquela conjuntura.

Para os intelectuais, era crucial a experimentação de alguns de seus projetos, como forma de garantir seu próprio reconhecimento entre os pares, além do papel significativo que vislumbravam para a reorganização da cultura escolar, contribuindo em última instância para a reorientação do projeto educativo de Estudos Sociais e particularmente dos saberes históricos que julgavam mais convenientes.

A implantação do Projeto era de ordem acadêmica e epistemológica, expandir o debate historiográfico para além dos muros da universidade, difundindo a teoria dos ritmos e durações do tempo - a "conceituação de ordem teórico-metodológica" - (UFPR. Relatório $\mathrm{n}^{\mathrm{o}}$. 1 , 1976, p.29), com vistas a um espectro mais amplo: tentava-se a superação da tendência teóricometodológica tradicional no ensino de História. A questão era traduzir os fundamentos braudelianos em um saber ensinável, articulando conteúdo e método e, desse modo, contribuir para uma nova prática e cultura escolares. 
Assim, o Projeto exerceria um papel fundamental na trajetória dos Estudos Sociais, no município, com efeitos para a disciplina escolar de História, pois ao retomar o contato com essa ciência de referência, atualizando os embates historiográficos, revelava a existência de uma tendência de reorientação não apenas do ensino de Estudos Sociais, mas do próprio ensino de História, na medida em que se orientava prioritariamente por essa - "o fio condutor" (UFPR. Relatório $\mathrm{n}^{\circ}$. 1, 1976).

A simples existência do Projeto sinaliza, portanto, para a contradição existente entre os pressupostos epistemológicos de uma historiografia escolar marcada ideologicamente pelo culto da Nação e assente no dogmatismo implícito da "verdade" da velha narrativa escolar e de um discurso renovado da historiografia, que incorpora diferentes agentes históricos, abordagens e temáticas.

Outra questão a considerar é a representação sobre os Estudos Sociais que aparece em grande parte na historiografia analisada, no sentido de que sua implantação promoveu a fragmentação e esvaziamento dos conteúdos das Ciências Humanas nos currículos.

É no contexto dessa representação sobre os Estudos Sociais e suas práticas escolares que se formulou o Projeto, em busca da superação dessas lacunas, orientando especialmente sua estruturação pela relação conteúdo e método.

As experimentações, ${ }^{7}$ realizadas com o apoio de alguns historiadores, adequando a proposta pedagógica dos Estudos Sociais às finalidades e conteúdos que julgavam mais convenientes evidenciam que a institucionalização dos Estudos Sociais não foi homogênea, desde a implantação da reforma educacional.

Por outro lado, se a "desvalorização" da área de humanidades tivesse ocorrido apenas como um efeito da implantação dos Estudos Sociais, por conta dos ideais de segurança nacional e dos objetivos de desenvolvimento econômico, como argumenta Fonseca (1995), como poderia ser explicada a tendência a pouca valorização das disciplinas de História e Geografia nas grades curriculares, mesmo após as mudanças da década de 1980, com o retorno dessas disciplinas escolares ao currículo do primeiro grau? Sua (re)valorização, na prática escolar, ainda enfrenta dificuldades, mantendo-se o privilégio das disciplinas oriundas das ditas ciências "duras", que detêm cargas horárias mais elevadas nas grades curriculares, face aos imperativos político-econômicos que privilegiam os interesses de uma cultura pragmática no capitalismo.

Além disso, o fundamento teórico que orientou a "integração" da História e de outras disciplinas, criticado pelo viés político daquele contexto histórico (1970-1980) como um traço que a desvalorizava - a interdisciplinaridade -, resultando na fragmentação dos conteúdos,

\footnotetext{
${ }^{7}$ Experimentações com os Estudos Sociais, contando com a participação de historiadores, ocorreram também em outros locais, como em São Paulo. (Ver: MARTINS, 2002).
} 
de certo modo, progressivamente, passou a ser incorporado ao discurso educacional e às experiências escolares. Obviamente adequando-se a apropriação e significado do contexto histórico, conforme os fundamentos específicos que os norteiam, mesmo após a emancipação das disciplinas escolares. Isso se deve ao desenvolvimento de novos paradigmas que passam a orientar a produção do conhecimento na área das Ciências Sociais com efeitos no campo educacional.

Nesse sentido, a noção de interdisciplinaridade subjacente aos Estudos Sociais teria presença naquele discurso curricular, não apenas do ponto de vista formal de estruturação das disciplinas, integrando difusamente os conhecimentos sobre as humanidades, mas como princípio teórico-epistemológico, pressupondo a aproximação das Ciências.

Essa perspectiva é retomada nas décadas de 1980 e 1990 - na elaboração das propostas curriculares regionais, aparecendo também nos Parâmetros Curriculares Nacionais - PCN (MEC, 1998; 1999). Assim, mesmo no ensino médio, onde os conteúdos de humanidades tradicionalmente são trabalhados como disciplinas escolares autônomas, os PCN defendem a sua superação.

Tais princípios são a base que dá sentido à área de Ciências Humanas e suas Tecnologias. O trabalho e a produção, a organização e o convívio sociais, a construção do "eu" e do "outro" são temas clássicos e permanentes das Ciências Humanas e da Filosofia. Constituem objetos de conhecimento de caráter histórico, geográfico, jurídico, sociológico e, sobretudo, filosófico. Já apontam, por sua natureza, uma organização interdisciplinar. Agrupados e reagrupados a critério da escola, em disciplinas ou em projetos e atividades que superem a fragmentação disciplinar tais temas e objetos, ao invés de uma lista infindável de conteúdos a serem transmitidos e memorizados, constituem a razão de ser do estudo das Ciências Humanas (MEC/SEM. PCN, 1999).

A defesa do princípio teórico-metodológico, portanto, naquela conjuntura reformadora municipal, acompanhando os avanços do campo historiográfico, aproveitava-se de uma oportunidade para tentar promover uma mudança no ensino das humanidades, na medida em que os pressupostos da tendência historiográfica francesa poderiam ser conciliados com a proposta oficial de implantação dos Estudos Sociais.

A propósito do envolvimento de intelectuais no processo das reformas, essa já era uma tradição desde os movimentos reformistas das primeiras décadas do século XX e, no que se refere à década de 1970, Maria do Carmo Martins lembra outros autores ${ }^{8}$ que mencionam a atuação de "professores universitários, alguns deles autores de materiais educativos, e

${ }^{8}$ BALZAN (1973); CUSINATO (1987). 
especialistas em educação, procurando 'melhorar' a proposta inicial realizada pelo CFE [Conselho Federal de Educação], ajudando a construir programas curriculares e procurando legitimar os ES [Estudos Sociais] como matéria de ensino, principalmente para as 4 séries do ensino fundamental" (MARTINS, 2003, p.157).

Esta autora, em outra obra, também alerta para a aproximação entre os professores universitários e os professores de ensino básico, na conjuntura da reforma escolar de 1971. Tal intervenção ocorreu como uma das estratégias utilizadas pelos intelectuais, quando surpreendidos pelas alterações que afetavam não só a formação acadêmica como os conteúdos escolares na área de humanidades, assumindo a responsabilidade de elaboração de propostas curriculares, junto aos órgãos do Estado, como forma de ocupar seu lugar social de intelectuais na definição de conteúdos e finalidades do ensino de História (MARTINS, 2002, p.187).

No Projeto investigado a participação dos intelectuais revela uma tentativa de (re) direcionamento do projeto educativo oficial, rumo aos avanços teórico-metodológicos da historiografia, em que pese o traço também alternativo da própria tendência historiográfica selecionada pelo mesmo, aliás, aspecto que a legitimaria como opção teórica, naquele contexto político-social mergulhado nos ideais da segurança nacional. A expressão de Aymard a propósito dos Annales como um "terceiro caminho alternativo" que permitiria o distanciamento tanto do marxismo como de outras influências, reforça tal reflexão (AYMARD, 2003, p. 17).

Reis (2000a), assim como Aymard, argumenta que a nova História identifica-se com a recusa confessada ou não, da ideia de revolução e tudo o que ela implica: aceleração do tempo dos eventos e acontecimento especulativo do sentido da história. Assim, a história da longa duração enfatiza os movimentos lentos, representando, ao contrário, uma desaceleração das mudanças, uma recusa à brusca revolução. Desse modo, o referencial teórico que dava sustentação ao Projeto "Estudos Sociais a partir da longa duração" não se colocava como uma ameaça concreta à política do regime militar.

É interessante destacar que o contexto histórico daquela reforma escolar corresponde à "fase áurea da repressão", justamente o momento em que começa a despontar a oposição armada contra o regime militar. Não obstante, apesar de o Estado viver o "período do terror", essa é a fase em que se obtém o maior grau de consenso e de legitimação social. O que motivava tal legitimação? Segundo Germano (2000), esse período corresponderia aos êxitos da política econômica colocada em prática pelo governo - o chamado "milagre econômico" e também a um movimento de repúdio por parte da sociedade aos atentados, assaltos a bancos, sequestros e ações armadas realizadas pelas organizações de esquerda.

Nesse sentido, as evidências parecem apontar para uma conciliação de interesses. $O$ contexto político exigia reformas e os intelectuais desejavam contribuir para a realização de 
um projeto educativo coerente com os avanços da ciência de referência. Um dos entrevistados argumentaria que os Estudos Sociais apresentavam dificuldades de operacionalização para os professores, daí o imperativo em encontrar uma alternativa para operacionalizar o princípio de integração, na medida em que os professores continuavam a trabalhar com a História e a Geografia separadamente (ALMEIDA, 2006). Desse modo, teria havido uma conjugação de interesses entre os professores universitários e os professores municipais, no sentido de se pensar uma proposta naquela área de conhecimento escolar, reforçando a hipótese de que a intervenção teve um caráter tático (CERTEAU, 1994), assumindo-se como uma manifestação ativa, na forma de readequação da ordenação legal.

Cabe neste momento discutir como foi efetivamente implantado o Projeto, que transformações são apontadas para o "novo" discurso curricular, sob a configuração dos Annales, em contraposição ao "velho" discurso historiográfico escolar do currículo oficial? Como o Projeto foi colocado em prática?

\section{Os Estudos Sociais nas escolas municipais de Curitiba}

A implantação dos Estudos Sociais na rede municipal de ensino local teria ocorrido através de dois projetos educativos que tiveram existência paralela. Primeiro, o Plano Curricular da Diretoria de Educação, elaborado estrategicamente por técnicos municipais, estruturado no campo político, fornecendo orientações para todas as áreas de ensino e no que concerne aos Estudos Sociais (História e Geografia) não apresentava diferenças importantes em relação aos currículos tradicionais. Segundo, o projeto "Estudos Sociais a partir da longa duração", elaborado taticamente, no campo acadêmico, por intelectuais da Universidade Federal do Paraná, implantado em 1975 em algumas escolas municipais sob o aval da Diretoria de Educação, objeto de reflexão neste artigo.

As primeiras escolas envolvidas no Projeto foram: em 1975 - Omar Sabbag (nordeste) e Albert Schweitzer (sudoeste); e em 1976 - Papa João XXIII (oeste) e Júlia Amaral Di Lena (norte). Aos poucos algumas unidades que implantavam as séries finais do primeiro grau, em atendimento à reforma, aderiram ao Projeto, assim como escolas de $1^{\mathrm{a}}$ a $4^{\mathrm{a}}$ série, com o propósito de unificar o ensino nessa área de conhecimento, desde as séries iniciais.

A visão panóptica que a história proporciona permite afirmar a permanência do Projeto por cerca de uma década, apesar de apontarem um declínio relativo ao longo do tempo. Em 1979 atingia 32,2\% das escolas municipais e em 1982 o índice havia caído para 21,5\% (PMC, 1979: 6-7; 1982:12;17). Há registros do Projeto até meados da década de oitenta quando, sob o impacto do movimento de educadores nacionais pelo retorno da História e da Geografia 
como disciplinas autônomas no currículo de primeiro grau, o Conselho Estadual de Educação aprovou parecer, argumentando que já existia o amparo legal para se trabalhar os Estudos Sociais com as disciplinas separadas, desde que se "respeitasse o princípio de integração que fundamenta o currículo". ' (PARANÁ, CEE. Parecer $n^{\circ}$ 332/84, 1983:9). Em decorrência, a área de Estudos Sociais não seria extinta, mantendo-se sua rubrica, mas a História e a Geografia poderiam ser trabalhadas separadamente, dando-se legitimidade a uma situação que, de fato, já existia na prática escolar em muitas escolas.

Em 1986, Resolução do Conselho Federal de Educação aprovou a separação definitiva das disciplinas de História e Geografia (BRASIL. CFE. Parecer $\mathbf{n}^{\circ} 785 / 86$ anexo à Resolução $\mathbf{n}^{\circ}$ 06/86) e, a seguir, o Conselho Estadual de Educação aprovou a Deliberação $n^{0} 0047 / 87$, que estabelecia "Normas para reformulação do Núcleo Comum para os Currículos do $1^{\circ}$ e $2^{\circ}$ graus, no Sistema Estadual”. Em 1988 foi publicado o "Currículo Básico - Uma contribuição para a Escola Pública Brasileira” (PMC/SME, 1988), para o município de Curitiba, o qual propõe uma nova concepção das áreas de estudo, procurando aproximar as disciplinas das ciências de referência.

Ora, diante disso, como a reforma dos anos setenta se realizara efetivamente nas escolas municipais? Como o Projeto foi colocado em prática? É através da análise das estratégias e táticas (CERTEAU, 1994) utilizadas nesse processo de institucionalização da área de Estudos Sociais que se tentará responder a essas questões.

\subsection{A estratégia do discurso curricular}

A eficácia da experiência alternativa foi procurada através de algumas medidas estratégicas gerais formuladas no campo político: a formulação de um currículo prescritivo (o projeto "Estudos Socais a partir da longa duração"), a formação continuada dos professores e um processo controlado de acompanhamento e avaliação unificada em todas as escolas envolvidas. Este artigo discutirá mais o primeiro aspecto - o currículo.

As transformações pelas quais passavam as sociedades brasileira e paranaense, no contexto de desenvolvimento das relações do capitalismo industrial e urbano, não mais favoreciam o processo educacional e o ensino das humanidades, baseados apenas na erudição e memorização. Ao contrário, impunham uma perspectiva de aprendizagem orientada para a capacidade de abstração, para a solução de problemas, captada pelos intelectuais na esteira dos princípios da escola nova.

\footnotetext{
${ }^{9} \mathrm{O}$ amparo legal era dado pelo Parecer federal $\mathrm{n}^{\circ} 7676 / 78$.
} 
O Projeto tinha uma motivação contingencial, atender à ordenação legal, porém adequando-a aos interesses acadêmicos, especialmente com relação à organização interdisciplinar de conteúdos, tendo a história como "fio condutor" (UFPR, 1976:43) de modo a intervir nas formas de apropriação de Estudos Sociais presentes até então.

O estudo (...) visa a corrigir as distorções do ensino tradicional de Estudos Sociais, principalmente em face dos dispositivos da Lei $\mathrm{n}^{\circ}$ 5692/71, que pretendem, para algumas séries, a integração das matérias fornecidas aos alunos, a hierarquização dos pré-requisitos e das situações de aprendizagem, atendidas às noções prescritas pela Psicologia Evolutiva" (UFPR, 1976, p. 29).

A proposta pedagógica está pautada em pressupostos psicológicos que valorizam os interesses do aluno, embora o atendimento das transformações no perfil do aluno com a massificação da escolarização constituísse uma complexidade para a escola. A crença de que o ensino baseado simplesmente na erudição não dá mais conta das necessidades sociais, coloca como um imperativo a maior aproximação dos saberes escolares à realidade do aluno que tem acesso à escola. Daí, possivelmente a articulação dos conteúdos, no Projeto, com os aspectos da vida cotidiana, conforme noção braudeliana de vida material. ${ }^{10}$

A análise dos conteúdos no Projeto impõe retomar um aspecto do currículo ressaltado por Apple, que o entende sempre como fruto de uma seleção: "nunca é um conjunto neutro de conhecimentos [...] é sempre [...] resultado da seleção de alguém, [...]. É produto de tensões, conflitos e concessões culturais, políticas e econômicas que organizam e desorganizam um povo" (APPLE, 1995, p. 59). Daí a escolha de determinada tradição que valorizava as categorias das durações e ritmos temporais e a aproximação das Ciências Sociais (BRAUDEL, 1970; 1972).

Do ponto de vista pedagógico, a expectativa do Projeto é "em termos dos conceitos que o aluno deverá elaborar, como primeiro passo para a formação de comportamentos mais complexos, bem como sua interiorização" ${ }^{11}$, os quais devem ser trabalhados a partir dos "esquemas que o aluno já possui, pois a matéria atua sobre experiências que o próprio aluno vivencia, como indivíduo em sociedade" (UFPR/ D.H, n.3, 1977:22-23). Assim, os critérios de seleção de conteúdos foram definidos a partir da teoria de desenvolvimento dos estágios cognitivos piagetianos, baseando-se em interpretação de Presseinsen \& D’ Amico (1975), que consideram a dimensão pessoal e social em sua relação com a faixa etária do aluno.

\footnotetext{
${ }^{10}$ A vida material ou civilização, para Braudel (1995), envolvia três campos: o meio ambiente das sociedades; as bases materiais do cotidiano - alimentação, vestuário, moradia -; e as técnicas.

${ }^{11}$ Esta concepção está fundamentada em HIRST, P.H. \& PETERS,R.S. A lógica da educação. Rio de Janeiro, Zahar Editores,1972, acreditando-se que "não pode haver experiência ou conhecimento sem a aquisição dos conceitos pertinentes" (UFPR,1976, p. 22).
} 
Nessa perspectiva compreende-se que o aluno deverá chegar ao conhecimento da realidade social não pelos fatos (curta duração), mas pela compreensão das estruturas (de longa duração), que estão presentes na vida humana e são pautadas pela vivência cotidiana; e pelas conjunturas (de média duração) que tornam compreensível o tempo social e individual (UFPR, 1976, p.18; 43). A opção pelo referencial teórico braudeliano permite trabalhar os conteúdos conceitualmente e a partir de temas próximos à realidade cotidiana do aluno, em seu caráter estrutural, mobilizando o seu interesse.

O eixo temático era o Homem vivendo em Sociedade, (UFPR, 1976, p.15; 18), a partir dos quais foram selecionadas as matrizes geradoras (UFPR, 1976, p.16; 45). Primeiramente, indicou-se o estudo das estruturas, as tendências seculares - de ritmo equivalente ao tempo geográfico tendências marcadas pelas permanências na vida cotidiana do homem (mais próximas da experiência do aluno), e onde mais facilmente se apreende as regularidades, as quais deveriam ser trabalhadas especialmente nas séries iniciais $\left(1^{\mathrm{a}}\right.$ a $4^{\mathrm{a}}$ séries), a partir de atividades e do eixo: "A vida de todos os dias", vista nas dimensões econômicas, históricas, geográficas, socioculturais e políticas (UFPR, 1976, p. 46-57).

A seguir, se propunha o estudo mais detalhado de "O homem brasileiro" e suas necessidades fundamentais como ser vivo e ser humano; as estruturas de longa duração, a serem trabalhadas nas séries finais ( $5^{\mathrm{a}}$ a $8^{\mathrm{a}}$ séries), através de áreas de estudo, com o eixo desdobrado em estruturas etnoculturais; estruturas geográficas; e necessidades básicas: o aprovisionamento, a estrutura da habitação, a estrutura da veste (UFPR, 1976, p.46-57).

E, por último, vinha o estudo das conjunturas e acontecimentos de média e curta duração o tempo social e individual - que se destinava ao $2^{\circ}$ grau, que deveria ser trabalhado através de disciplinas, focalizando o eixo: "O Homem" - "A Sociedade no Tempo", analisados "nos diversos aspectos estudados pelas Ciências Sociais" (UFPR, 1976, p.46-57). ${ }^{12}$

Desse modo, a partir do eixo central - o Homem em Sociedade - e das variáveis Tempo e Sociedade definiram-se as matrizes geradoras, coerentes com a multiplicidade temporal, as quais foram revisadas no experimento da $3^{\text {a }}$ fase em 1977 , no que se refere ao ensino da $1^{\mathrm{a}}$ a $8^{\text {a }}$ série: $^{13}$

a) "realidades de longa, muito longa duração", que constituem as tendências seculares a serem estudadas como atividades através dos

\footnotetext{
${ }^{12} \mathrm{O}$ “modelo matricial” obedecia a uma hierarquização de conteúdos e integração das ciências sociais "para todo o primeiro e o segundo graus", embora a rede municipal de ensino atendesse apenas o $1^{\circ}$ grau. Assim, para o $2^{\circ}$ grau é apenas indicada a matriz ampla - O Homem - com a observação de que seus temas poderão ser desdobrados e ampliados a partir dos níveis anteriores.

${ }^{13}$ A primeira fase se deu em 1975, com experimento na $5^{\text {a }}$ série; a segunda fase ocorreu em 1976, com revisão do experimento da $5^{\mathrm{a}}$ série e sua adequação para a $4^{\mathrm{a}}$ série e ampliação para a $6^{\mathrm{a}}$ série; e a terceira fase em 1977 com revisão dos experimentos anteriores, sua adequação e ampliação para as demais séries (UFPR. 1977, p.25). As etapas posteriores até 1985 permaneceram sob a coordenação da administração municipal, não mais contando com a supervisão direta da universidade.
} 
temas: "As necessidades básicas do homem". "A vida de todos os dias" $\left(1^{\mathrm{a}}, 2^{\mathrm{a}}\right.$ e $3^{\mathrm{a}}$ série); "Necessidades básicas do homem brasileiro" ( $4^{\mathrm{a}}$ série); b) "estruturas de longa duração", estudadas como áreas de estudo com os temas: "As sociedades" ( $5^{\mathrm{a}}$ série); "O trabalho e as técnicas" (6 $6^{\mathrm{a}}$ série); "Os espaços, as economias e as trocas" ( $7^{\mathrm{a}}$ série) e "As ciências" ( $8^{\mathrm{a}}$ série); c) "conjunturas, acontecimentos de média ou curta duração", estudadas como disciplinas, através do tema: "O homem" ( $2^{\circ}$ grau). (UFPR, 1977, p. $25 ; 35 ; 74)$.

Os planos de ensino eram elaborados pelos consultores, técnicos municipais e professores municipais envolvidos no Projeto, que participavam do planejamento à execução e avaliação. Essa centralização das decisões deve-se, de um lado, à exigência de controle da experiência por parte dos pesquisadores, e, de outro lado, pelo imperativo da regulação social, no qual o domínio e a legitimação constituíam-se parceiros fundamentais.

Embora a proposta não possa escapar a críticas, é possível perceber um esforço em manter a coerência teórico-metodológica. Ao propor-se o trabalho com as durações temporais e com a aproximação das Ciências Sociais, pretendia-se possibilitar uma leitura histórica total, viabilizando-se a reflexão sobre a realidade social nas suas várias dimensões - econômica, histórica, geográfica, política, sociocultural. Acreditava-se que este princípio permitiria que a sociedade, inicialmente vista numa perspectiva local, pudesse gradativamente ser estudada de forma comparativa a outros recortes espaciais e temporais.

\subsection{As táticas na prática escolar}

O que teria ocorrido no cotidiano da sala de aula com os Estudos Sociais? Haveria indícios de renovação metodológica em suas práticas? Ao serem indagados sobre as atividades realizadas no cotidiano escolar, os entrevistados mencionavam de imediato a estruturação por objetivos das propostas curriculares. Registrou-se na memória que, mesmo o Projeto, que teria uma finalidade intelectual, visando o exercício de certa razão crítica, instigando o aluno a uma "análise mais contextualizada, embora não tivesse a crítica marxista ou a crítica ao sistema" (SOUZA, 2006), trazia a característica "tecnicista" de uma das orientações pedagógicas então dominantes, que se revelava na ênfase ao planejamento e à avaliação por objetivos e no processo pedagógico pautado por técnicas de ensino.

A forte influência do planejamento é um traço destacado por Gonçalves (2012) na administração daquele período, como uma das diretrizes da Escola Superior de Guerra (ESG) para a tomada de decisões, seja no campo político ou técnico, tendo em vista as finalidades de desenvolvimento econômico e social: 
Cabe [...] ressaltar o detalhamento acerca do Planejamento, definido como "a atividade permanente e continuada, que se desenvolve de modo ordenado e racional, sistematizando um processo de tomada de decisões" (ESG, 1975: 537), que abrange ações políticas e técnicas. Quando envolver "atividades de setores ou órgãos diversos, mas interdependentes, persiste não só a necessidade de coordenação, mas também a de integração das ações planejadas pelos diversos setores" (ESG, 1975, p.538, apud GONÇALVES, 2012, p.14).

A finalidade de constituição de uma cidadania social mais ampla ficava limitada pelo quadro geral dos dispositivos estratégicos da regulação social, que se orientava mais por interesses políticos da modernização conservadora, centrada nas estratégias de racionalização e controle, tendo em vista o desenvolvimento do capitalismo, do que pelo interesse em desenvolver uma formação sólida e a capacidade intelectual dos alunos.

Assim, cabe pensar se o Projeto permitiu efetivamente a reorientação dos "fazeres ordinários" como diz Certeau (1994) nas salas de aula.

O discurso prescritivo do Projeto propunha o desenvolvimento intelectual do aluno, defendendo que a "estrutura da matéria de Estudos Sociais favorec[eria] uma série de operações: observar, relacionar, relatar, experimentar, induzir, colecionar, comparar, analisar, inferir e extrapolar" (UFPR, 1977, p.100). Esse interesse estava implícito também na concepção de aluno, na sua representação como sujeito ativo: "o princípio da atividade do aluno, no sentido de ser este o principal agente na construção do conhecimento de sua própria aprendizagem" (UFPR. 1977, p. 100).

O relatório de uma das escolas a respeito da sua experiência com o Projeto revela, com efeito, a aplicação desse princípio ativista para alcançar o desenvolvimento intelectual do aluno, com ênfase à exploração do cotidiano da criança, e também aponta indícios de uma preocupação com a aquisição de conceitos, já nas séries iniciais:

[...] partimos do cotidiano do aluno, daquilo que ele tem conhecimento para o desconhecido e depois para a elaboração dos conceitos. (...). Em comparação com as turmas tradicionais, das quais também sou professora, noutro Estabelecimento, as turmas do Projeto apresentam uma capacidade de elaboração de conceitos e formação de frases superior e em tempo mais curto (PMC/D.E. Escola Omar Sabbag. Relatório, 1976, p.1). (Grifo nosso).

Os pressupostos da escola nova estavam presentes em várias fontes, orientando o discurso e a prática escolar, perpassados por elementos da pedagogia tecnicista. "Era a 
escola nova. E eu também fui uma pessoa empolgada. Então, a gente usava muitas práticas de dinâmica de grupo [...], entrando no meio deles para discutir determinados temas, elaborar algum trabalho, corrigir exercícios". (SOUZA, 2006).

Outra estratégia metodológica registrada pelos depoentes era a "pesquisa", que aparece na fala dos depoentes e nos Relatórios de Atividades das escolas. Entretanto, para o Souza, eram pesquisas bibliográficas, limitadas pelas condições estruturais da escola pública, cuja biblioteca possuía um acervo precário. E, também, não era uma prática comum a todos. Sob a forma de microrresistências, alguns professores colocavam-se numa situação de acomodação e de conservação das práticas tradicionais, recusando-se a mudanças. Diz ele: [...]"acho que foi até um trabalho interessante de fazer a criança [...] ler, ter a capacidade de fazer a síntese, mas [...] recordo [...] tinha professores que faziam isso [...] e professoras que não faziam... (SOUZA, 2006).

Almeida, entretanto, recupera outro significado para a prática de pesquisa - a experiência. Através dela tentava-se, por exemplo, conduzir a criança à compreensão da noção temporal, na perspectiva de superação da concepção tradicional de tempo cronológico, desenvolvendo a sua capacidade de observação, instigando-as a estabelecer relações entre o presente e o passado, buscando as permanências e mudanças, embora com ênfase no cotidiano. ${ }^{14}$ Elas eram incentivadas a realizar observações, coletar informações, a se manifestar oralmente e a sistematizar na escrita o que tinham discutido. "Pesquisávamos dentro da comunidade também, não era só pesquisa bibliográfica”. (ALMEIDA, 2006).

É interessante que já se evidenciava uma tentativa de formar o aluno para a prática de uma pesquisa mais sistemática, usando-se também o recurso da História oral, embora nos limites do empírico, da faixa etária e nível de ensino com os quais trabalhavam e das condições das escolas municipais. "Eles faziam pesquisas, entrevistas, levavam pessoas [...] que poderiam dar uma contribuição para a história daquela comunidade”. (ALMEIDA, 2006).

Os depoimentos não permitem afirmar a presença de uma consciência sobre a relação de ensino e pesquisa na escola de primeiro grau como norte da atividade pedagógica para a produção de um saber histórico escolar, como aparece em propostas pedagógicas mais recentes para o ensino de História. Mas, de qualquer modo, já constituíam alguns indicativos de que a prática escolar estava se transformando.

Com efeito, havia vestígios táticos da superação da prática tradicional, no sentido de orientar o aluno para a reflexão sobre a realidade que o circundava, para o desenvolvimento da capacidade de buscar informações já produzidas ou não, e para sistematizá-las. A prática de pesquisa, a preocupação com a aquisição de uma linguagem conceitual e a finalidade do

\footnotetext{
${ }^{14}$ A leitura de Braudel influenciava essa abordagem com sua discussão sobre a noção de civilização e vida material, onde o cotidiano tinha um papel significativo por esse historiador acreditar que nele mais facilmente seriam apreendidas as regularidades sociais. Tal apropriação era reforça da na visão dos educadores pelo viés empírico da Psicologia da Aprendizagem.
} 
ensino voltada à autonomia intelectual do aluno não apareciam no projeto educativo oficial como se destacavam no projeto alternativo. Contudo, essas práticas não se constituíram como regra geral, pois dependiam da formação do professor e do seu modo de apropriação das "inovações" apresentadas.

Alguns aspectos negativos do Projeto foram apontados por professores das séries iniciais, como os que concernem: à complexidade dos objetivos, dos conteúdos e da metodologia; à linguagem inacessível à criança e difícil para o professor; à extensão dos conteúdos; à ausência de livros didáticos naquela concepção; à dificuldade para o professor realizar pesquisas para as suas aulas; ao tempo tomado pela área, prejudicando o ensino de outras (PMC. Relatórios de escolas, 1978; 1979; 1984). Ressalte-se que nem sempre o professor das séries iniciais tinha formação superior e muito menos de História.

Apesar das críticas, registros positivos permaneceram na memória dos depoentes, evidenciando o quanto o Projeto havia afetado professores e alunos. O relato de SOUZA (2006) indica a forte influência na sua própria formação:

\begin{abstract}
Eu, pessoalmente, posso confessar que foi talvez a coisa que mais mexeu comigo como professor de História, porque até aí eu também tinha uma visão muito factual da História. Depois (...) eu fui caminhar por uma linha mais marxista da História (...). Mas essa época isso me encantou, porque me dava uma perspectiva de visão de educação e da objetiva da História que antes eu não tinha.
\end{abstract}

Os depoimentos de ALMEIDA e TODESCHI (2006) são reveladores, no sentido da incorporação conceitual por parte dos alunos na prática escolar, assim como no desenvolvimento de sua capacidade criativa, interesse pelo conhecimento e exercício de raciocínio e julgamento, confirmando resultados do Relatório do Departamento de História (UFPR), a respeito do Projeto. Dentre estes se destacam: o aumento da criatividade nos trabalhos das crianças; maior estímulo por parte dos professores para transmitir o conteúdo; aquisição dos conceitos trabalhados, cujo resultado aferido na avaliação demonstrou um aproveitamento superior a $70 \%$, na maioria dos alunos; a metodologia desenvolvida permitiu não só a elaboração de conceitos, como em alguns casos levou a inferências e deduções; a presença da pesquisa como estratégia de ensino, no sentido de busca e interpretação de dados e formação de atitudes (UFPR, n.2, 1977, p.84). 


\section{Considerações Finais}

Da análise documental realizada pode-se inferir em primeiro lugar, que para atender às expectativas do desenvolvimento da sociedade, tendo em vista as novas demandas escolares e as novas configurações epistemológicas, era preciso pensar outro projeto educativo. Diante disso, os intelectuais justificavam-se: "O planejamento e a organização de currículos pretendem, justamente, conduzir as populações jovens segundo políticas socioeducacionais

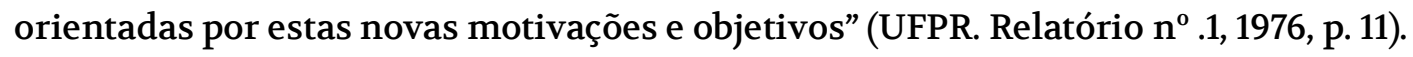

Os intelectuais envolvidos no Projeto integravam-se ao movimento epistemológico articulado com a ideologia do progresso, tanto por sua defesa de uma proposta educacional de "melhoramento social" (POPKEWITZ, 1997), atrelado aos interesses do capitalismo, como pelos pressupostos epistemológicos em que se apoiaram. Operaram através de um lugar estratégico, mas optaram por desenvolver uma tática de negociação de saberes e de procedimentos teórico-metodológicos expressos naquele Projeto, o qual embora não enfrentasse radicalmente os pressupostos da proposta oficial tinha potencialidade para sua superação, por fundamentar-se num modelo historiográfico também alternativo às outras correntes predominantes, o positivismo e o marxismo. Daí seu relativo sucesso naquele contexto de exceção.

O lugar social de suas falas foi, portanto, a academia e no interior desta um determinado marco teórico-metodológico. Politicamente, também, a liderança do projeto apresentava uma postura mais conservadora, daí sua fácil aproximação com as instâncias de poder.

Quanto à reação ao Projeto e ao seu uso na prática escolar, enquanto alguns professores o aceitaram entusiasticamente, por suas ligações com os intelectuais (ex-professores), sua formação acadêmica e interesse em desenvolvimento pessoal, outros tiveram dificuldades de apropriação ou resistiram à mudança, o que gerou procedimentos táticos de enfrentamento às ordenações, como preservar as práticas tradicionais ou fazer críticas diversas. As atitudes de microrresistência se concretizaram, por exemplo, numa determinada postura aparentemente passiva: alguns professores preferiam "passar o ponto" de História e de Geografia, separadamente, no quadro para os alunos, "transformando a aula em outra coisa" que não Estudos Sociais, como desvelam as "escrituras invisíveis" (CERTEAU, 1994) da memória de SOUZA (2006).

Em momentos de reforma educacional é elemento comum a oposição às mudanças nas práticas escolares. Naquele contexto, os atos de resistência expressavam mais a luta de representações sobre a prática pedagógica que atos de rebeldia consciente às políticas - 
educacional e social. Embora alguns professores municipais olhassem as políticas com desconfiança, eles não se mobilizaram contra o poder central. Suas táticas limitaram-se às microações articuladas contingencialmente no lugar praticado, ou seja, no interior da escola e da sala de aula, reinventando usos e procedimentos com os bens culturais, mas sem afetar de imediato a organização coletiva de poder.

Um movimento de reação mais organizado só se desenvolveu em meados dos anos oitenta, com a incorporação dos professores municipais ao debate nacional pelo retorno da História e Geografia ao currículo escolar, mas então o movimento de redemocratização já estava em curso.

Embora o período se caracterize como de autoritarismo e repressão, criando-se múltiplas estratégias de controle e dominação, como a própria institucionalização da área de Estudos Sociais no ensino de primeiro grau e a supressão de disciplinas escolares mais críticas do currículo do ensino de segundo grau, como a Filosofia e a Sociologia e a obrigatoriedade de cursos profissionalizantes nesse nível de ensino, os estudos sobre o período revelam que nem sempre as estratégias políticas do regime militar se revelaram com força suficiente para sua concretização exitosa, havendo sempre no campo educacional certa margem de autonomia, negociação e resistência que permitiu aos educadores enfrentarem este período com o uso de táticas diversas, seja de aparente adesão, reinvenção ou reação crítica.

Este foi o caso não só dos professores municipais como dos próprios intelectuais envolvidos no Projeto, os quais chamados a participar do processo de legitimação de uma estratégia política governamental optaram por uma tática específica. Fundamentando cientificamente o projeto governamental com os pressupostos teórico-metodológicos em tendência ascendente na historiografia deram-lhe relativa legitimidade, porém atenderam também aos interesses acadêmicos e conduziram uma proposta pedagógica alternativa a oficial, possível naquela conjuntura e mais próxima dos interesses de desenvolvimento educacional naquele contexto.

Para concluir, os resultados alcançados revelam que nem sempre as estratégias políticas do governo militar (1964-1985) tiveram o sucesso esperado, mesmo com a atuação de intelectuais, cuja intervenção pode ter servido para reforçar muitas vezes a manutenção de propostas mais conservadoras por tempo mais prolongado, mesmo introduzindo algumas mudanças para superação das práticas consideradas tradicionais. 


\section{Bibliografia e Fonte}

ABUD, K.M. O ensino de história como fator de coesão nacional: os programas de 1931. Revista Brasileira de História. São Paulo: ANPUH, v. 13, n. 25/26, p. 163-174, Set.1992/Ago.1993.

APPLE, M.W. A política do conhecimento oficial: faz sentido a idéia de um currículo oficial? IN: MOREIRA, A. F.; SILVA, T.T. (Org.) Currículo, cultura e sociedade. São Paulo: Cortez, 1995, p.59-91.

BITTENCOURT, C.M.F. Propostas curriculares de história: continuidades e transformações. IN: BARRETO, E.S.D. As propostas curriculares oficiais. São Paulo: Fundação Carlos Chagas, 1995. p. 97-114.

BRASIL. CFE. Parecer $n^{o}$ 7676/78, 1978.

BRASIL. Parecer $n^{0}$ 785/86, anexo à Resolução $n^{o}$ 06/86, 1986.

BRAUDEL, F. Civilização material, economia e capitalismo - séculos XV- XVIII. São Paulo: Martins Fontes, 1995. 3v.

BRAUDEL, F. História e Ciências Sociais. Lisboa: Editorial Presença, 1972.

CERTEAU, M. A invenção do cotidiano - 1. Artes de fazer. Petrópolis, Rio de Janeiro: Ed. Vozes, 1994.

CERTEAU, M. A invenção do cotidiano - 2. Morar, cozinhar. Petrópolis, Rio de Janeiro: Ed. Vozes, 1996.

CHARTIER, R. O mundo como representação. Estudos Avançados. São Paulo: Instituto de Estudos Avançados da Universidade de São Paulo, v.5, $\mathrm{n}^{\circ}$. 11, Jan./Abr. 1991. Disponível em: http://dx.doi.org/10.1590/S0103-40141991000100010.

CHARTIER, R. A história cultural. Entre práticas e representações. Lisboa: DIFEL, 1986.

CHEVALLARD, Y. La transposición didáctica. Buenos Aires: Aique, 1991.

CURITIBA. Prefeitura Municipal de. Departamento de Bem Estar Social. Diretoria de Educação. Relatório Geral de Atividades. Curitiba, 1975a.

CURITIBA. Prefeitura Municipal de. Departamento do Bem Estar Social. Diretoria de Educação. Plano Curricular. Volumes III-A e III-B. Curitiba, $1975 b$.

CURITIBA. Prefeitura Municipal de. Diretoria de Educação. Relatório Anual, 1979; 1982.

CURITIBA. Prefeitura Municipal de. Diretoria de Educação. Relatórios das escolas, 1976; 1978; $1979 ; 1984$.

CURITIBA. Prefeitura Municipal de. Secretaria Municipal de Educação. Plano de Educação da Secretaria Municipal de Educação para a gestão 1986-1988. Curitiba, 1986. 
CURITIBA. Prefeitura Municipal de. Secretaria Municipal de Educação. Currículo Básico Uma contribuição para a Escola Pública Brasileira, 1988.

FENELON, D. A questão dos Estudos Sociais. Cadernos CEDES. A prática do ensino de história, São Paulo: Cortez/CEDES, nº 10, 1984, p.11-22.

FONSECA, S.G. Caminhos da História Ensinada. 3. ed. Campinas, São Paulo: Papirus, 1995.

GONÇALVES, N.G. A Escola Superior de Guerra e a Lei 5.692/71: discursos governamentais e implementação da Lei no Paraná. IN: GONÇALVES, N.G.; RANZI, S. F. (Orgs.) Educação na ditadura civil-militar: políticas, ideários e práticas (Paraná, 1964-1985). Curitiba: Editora UFPR, 2012, p.10-28.

HIRST, P.H. \& PETERS, R. S. A lógica da educação. Rio de Janeiro, Zahar Editores, 1972.

JULIA, D. A cultura escolar como objeto histórico. Revista Brasileira de História da Educação. Campinas: Autores Associados, $n^{\circ}$. 1, 2001, p. 09-43.

MALINOWSKI, B. Uma teoria científica da cultura. Rio de Janeiro: Zahar, 1962.

NADAI, E. A Escola Pública Contemporânea: Os Currículos Oficiais de História e Ensino Temático. Revista Brasileira de História. São Paulo, v.6, nº. 11, Set.1985/Fev.1986, p. 99-116.

NADAI, E. O ensino de História no Brasil: trajetórias e perspectivas. Revista Brasileira de História da Educação. São Paulo: ANPUH, v. 13, nº. 25/26, Set.1992/Ago.1993, p. 143-162.

PARANÁ. CEE. Parecer $n^{0} .332 / 84,1983$.

PARANÁ. CEE. Deliberação $n^{0}$. 0047/87, 1987.

POPKEWITZ, (POPKEWITZ T. S. Reforma Educacional - uma prática sociológica. Porto Alegre: Artes Médicas, 1997.

PRESSEISEN, B. \& D' AMICO, J. A Functional Social Studies Curriculum Ephasizing Piagetian Operations. IN: The Educational Forum. Volume (39)2. Chicago, Ed. Kappa Delta Pi, Janeiro, 1975, p. 163-175.

SCHMIDT, M.A. e CAINELLI, M.R. Ensinar História. São Paulo: Scipione, 2004.

UNIVERSIDADE FEDERAL DO PARANÁ. Setor de Ciências Humanas, Letras e Artes. Departamento de História. Projeto de Estudos Sociais a partir da longa duração. Curitiba: UFPR, 1976/1977, 3 v.

VIANA, I. "Artes de fazer" na reforma escolar: o projeto de estudos sociais a partir da longa duração - Curitiba (décadas de 1970-1980). Tese (doutoramento). Setor de Educação/ UFPR, 2006.

WESTPHALEN, C. M. A introdução ao estudo da História e as técnicas auxiliares do historiador. IN: V Simpósio Nacional dos Professores Universitários de História. São Paulo: USP, 1968.

Entrevistas 


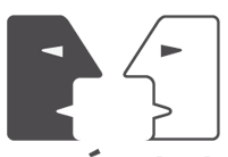

ANTÍTESES

ALMEIDA, M.E. Professora aposentada da Rede Municipal de Ensino de Curitiba. Entrevista concedida em Curitiba, 07 de março de 2006.

TODESCHI, E. Professora aposentada da Rede Municipal de Ensino de Curitiba. Entrevista concedida em Curitiba, 07 de março de 2006.

SOUZA, A.H. Ex-professor da Rede Municipal de Ensino de Curitiba. Entrevista concedida em Curitiba, 12 de maio de 2006.

WESTPHALEN, C. M. Professora da UFPR. Entrevista concedida em Curitiba, 23 de setembro de 2003. 